\title{
Predictive Contributions of Snowmelt and Rainfall to Streamflow Variations in the Western United States
}

\author{
Xiaohui Zheng $\mathbb{D},{ }^{1}$ Qiguang Wang $\mathbb{D},{ }^{2}$ Lihua Zhou, ${ }^{1}$ Qing Sun, ${ }^{3}$ and Qi Li ${ }^{4}$ \\ ${ }^{1}$ College of Global Change and Earth System Science, Beijing Normal University, Beijing 100875, China \\ ${ }^{2}$ China Meteorological Administration Training Center (CMA), Beijing 100081, China \\ ${ }^{3}$ College of Applied Meteorology, Nanjing University of Information Science and Technology, Nanjing 210044, China \\ ${ }^{4}$ School of Atmospheric Physics and Atmospheric Environment, Nanjing University of Information Science and Technology, \\ Nanjing 210044, China \\ Correspondence should be addressed to Qiguang Wang; wangqg@cma.gov.cn
}

Received 11 February 2018; Accepted 6 June 2018; Published 4 July 2018

Academic Editor: Brian R. Nelson

Copyright (c) 2018 Xiaohui Zheng et al. This is an open access article distributed under the Creative Commons Attribution License, which permits unrestricted use, distribution, and reproduction in any medium, provided the original work is properly cited.

\begin{abstract}
This study used long-term in situ rainfall, snow, and streamflow data to explore the predictive contributions of snowmelt and rainfall to streamflow in six watersheds over the Western United States. Analysis showed that peak snow accumulation, snow-free day, and snowmelt slope all had strong correlation with peak streamflow, particularly in inland basins. Further analysis revealed that the variation of snow accumulation anomaly had strong lead correlation with the variation of streamflow anomaly. Over the entire Western United States, inner mountain areas had lead times of 4-10 pentads. However, in coastal areas, nearly all sites had lead times of less than one pentad. The relative contributions of rainfall and snowmelt to streamflow in different watersheds were calculated based on the snow lead time. The geographic distribution of annual relative contributions revealed that interior areas were dominated by snowmelt contribution, whereas the rainfall contribution dominated coastal areas. In the wet season, the snowmelt contribution increased in the western Pacific Northwest, whereas the rainfall contribution increased in the southeastern Pacific Northwest, southern Upper Colorado, and northern Rio Grande regions. The derived results demonstrated the predictive contributions of snowmelt and rainfall to streamflow. These findings could be considered a reference both for seasonal predictions of streamflow and for prevention of hydrological disasters. Furthermore, they will be helpful in the evaluation and improvement of hydrological and climate models.
\end{abstract}

\section{Introduction}

The Western United States (WUS) is a semiarid region that covers more than half the land area of the U.S. [1]. This area, which receives little precipitation during summer, relies considerably on the wintertime precipitation phase and snowpack accumulation to sustain a multitude of ecosystem goods and services [2]. Thus, the regional ecology and economy are both vulnerable to water resource anomalies caused by seasonal hydroclimatic variations [3]. Recent hydrological disasters in the WUS have been closely related to climate change [4-6]. The occurrence probabilities of hydrological anomalies and of hydrological extremes have both increased [7]; these conditions have affected the regional agricultural production, the occurrence of forest fires, and the national socioeconomic development $[8,9]$. Therefore, it is of great importance to conduct accurate and effective hydrological forecasting for the WUS within the context of climate change.

Streamflow is a hydroclimatic variable that directly influences drought- and flood-related disasters. It is affected both by natural factors, such as the precipitation system, soil state, and land surface, and by human factors, including land use changes and water use efficiency. Because of the considerable reliance of the WUS on snow as a water resource, snow accumulation represents a factor of first-order importance regarding regional water supply [10]. Snowmelt contributes approximately $50 \%-80 \%$ of the total streamflow 
and is highly seasonal in nature, that is, the majority of streamflow occurs because of snowmelt during the late spring-summer (April-July) [11]. In western coastal areas, streamflow is derived mainly from rainfall. Therefore, streamflow variation in the WUS has strong correlation with changes in snowpack accumulation and rainfall and has obvious seasonal variation [11-14].

A considerable amount of research has been undertaken regarding the relationships between runoff and both precipitation systems and snowmelt. In addition, several studies have documented the correlation between oceanic climatic phenomena and streamflow. For example, Hunter et al. [15] reported a strong relationship of streamflow with ENSO and relatively weak correlations with the PDO, AMO, and NAO anomalies. Except for those that researched atmosphericoceanic circulations, most of the studies on the seasonal variation of streamflow focused on the relationship between runoff and snowmelt during the melting season. Snowmelt is related closely to the snowpack amount and temperature in winter and spring. The spring temperature can affect streamflow by influencing both the time of the onset of snowmelt and the snowmelt slope [16]. Recently, spring temperatures have demonstrated a warming tendency coincident with an earlier onset of snowmelt. Many researchers have started to focus on the relationship between early snowmelt and spring and summer runoff [17-20]. Some studies have suggested that warmer spring temperatures would lead to earlier onset of snowmelt and greater associated runoff, thereby resulting in increased spring streamflow and decreased summer streamflow [19, 21, 22]. Jeton et al. [23] derived the same conclusion, believing that early snowmelt occurred when vegetation was less active. They claimed that such inactivity disrupts the synchronicity between the water availability and demand, resulting in greater springtime streamflow. Conversely, Bosson et al. [24] thought that earlier snowmelt might contribute more to evapotranspiration (ET) than to streamflow because of the increased vapor pressure deficit due to atmospheric warming, which would result in a lower-than-usual springtime streamflow. Recent findings by Trujillo and Molotch [25] indicated that reduced levels of solar radiation available for driving snowmelt earlier in the year could produce slower rates of snowmelt and decrease the generation of streamflow during the spring.

Based on the relationship between snowmelt and streamflow, snowmelt could be used as a significant predictor of streamflow. However, previous studies simply revealed the possibility of this phenomenon and consequently outlined its potential mechanisms without achieving a uniform conclusion. In addition, earlier work focused primarily on changes in the timing of snowmelt without considering the effects of other snow metrics or of the memory of snowmelt on streamflow. Furthermore, the research cited in this study was based either on the hydrologic situation of the entire WUS or on that of a specific watershed. Therefore, this study separated the WUS into six watersheds and selected eight snow metrics to both investigate the relationships among the snow metrics and streamflow and to determine the lead correlation between the snowpack and streamflow in each watershed. The findings of this research demonstrate the potential for the use of snow variations to predict streamflow changes in advance.

In addition to snowpack, rainfall represents another important predictor of streamflow in the WUS. However, because the contributions of rain-derived runoff (also called rainfall contribution, referred to as $f_{\text {rain }}$ hereafter) and of snow-derived runoff to the total runoff (also called snowpack contribution, referred to as $f_{\text {snow }}$ hereafter) are different in each area; both $f_{\text {rain }}$ and $f_{\text {snow }}$ have different contributions to streamflow. Previous studies focused primarily on $f_{\text {snow }}[10]$. In addition, in most of those studies, $f_{\text {snow }}$ was calculated based on metrics such as the total snowfall as a fraction of total precipitation, the total snowfall as a fraction of total runoff, or melt season runoff as a fraction of total annual runoff [26]. Partly because of differences among the methods by which $f_{\text {snow }}$ was approximated, large variations in the estimates have been reported. For example, most research has reported that snow contribution ratio was 75\% [27-31], whereas other studies have produced values in the ranges of $40 \%-60 \%$, 50\%-80\%, or $60 \%-90 \%$ [17, 32-34]. Compared with such ratio metrics, the following methods are considered more reasonable. Li et al. [10] quantified $f_{\text {snow }}$ by tracking the fate of snowmelt in modeled hydrologic fluxes and obtained gridded model results. Through calculations of the long-term probability of snowmelt pulse occurrence (i.e., if the snowmelt pulse occurred during the period between the 150th day and the 250th day of the water year), Fritze et al. [35] divided streamflow sites into four categories: clearly rain dominated, mostly rain dominated, mostly snowmelt dominated, and clearly snowmelt dominated. This study used a new method to calculate $f_{\text {rain }}$ and $f_{\text {snow }}$ at each streamflow site both during an entire year and during the wet season to provide a more accurate basis for a seasonal prediction of streamflow.

To achieve qualitative and quantitative seasonal predictions of streamflow, this study considered three issues based on long-term observational data. First, among the eight snow metrics used widely throughout the literature, those that have significant correlations with the peak streamflow were selected. Second, the lead correlation between the SWE and streamflow at each stream site was calculated. Third, the relative contributions of rain and snowmelt to streamflow were quantified. These findings will provide a basis for seasonal streamflow predictions and benefit the evaluation of hydroclimatic models. The remainder of this paper is organized as follows. Descriptions of the study area and of the observational data are provided in Section 2. The methods adopted for the analysis of the data are presented in Section 3. Section 4 presents the results with respect to the three issues listed above. Finally, the conclusions are summarized in Section 5.

\section{Research Area and Data}

This study focused on six hydrologic regions of the WUS which correspond to USGS Regions 13-18 (https://water. usgs.gov/GIS/regions.html): Rio Grande (RG), Upper 


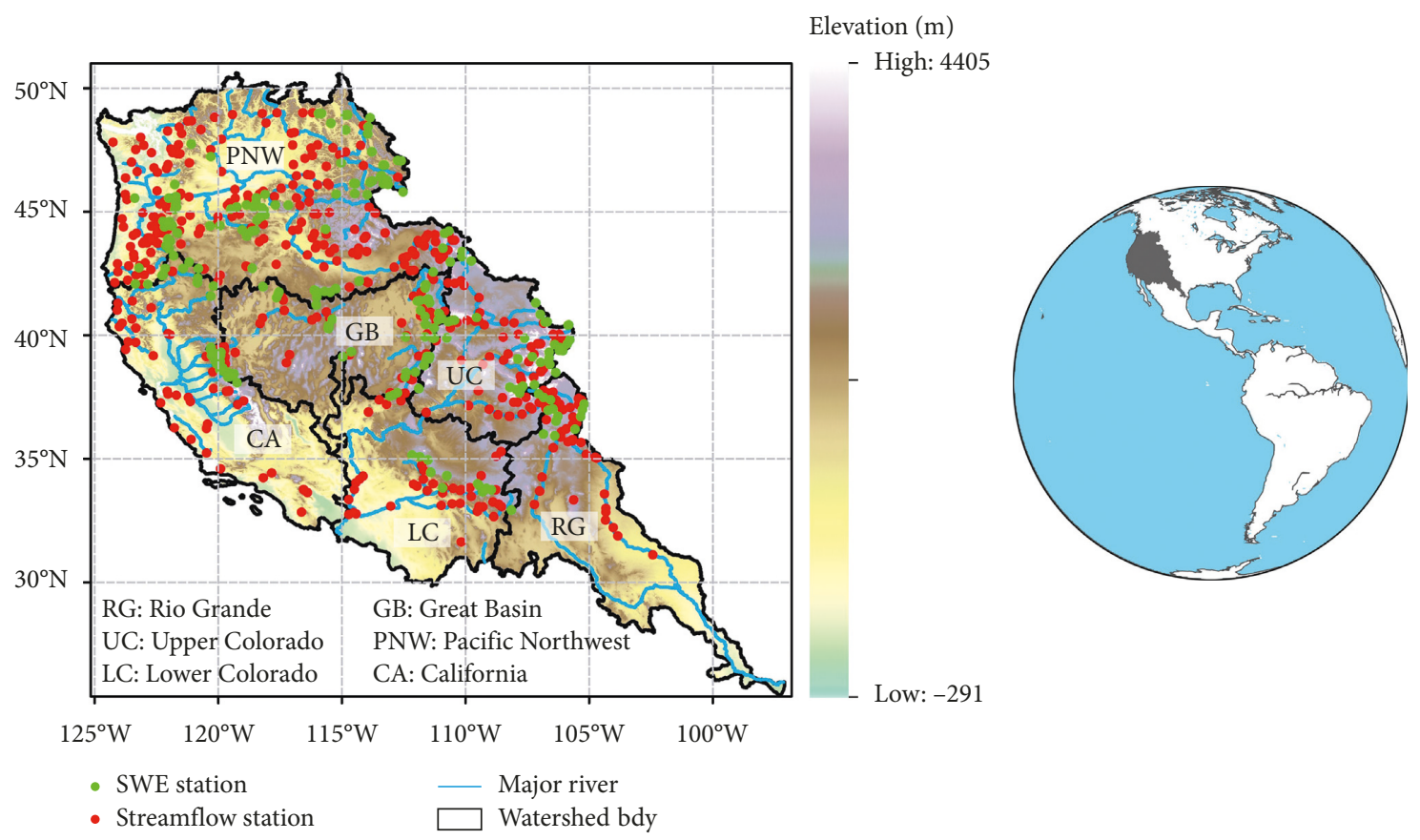

FIGURE 1: Research area, station distribution, and the location of the study area in global (gray area in western hemisphere).

Colorado (UC), Lower Colorado (LC), Great Basin (GB), Pacific Northwest (PNW), and California (CA). The distribution of the watersheds and details of their elevations and major rivers are illustrated in Figure 1.

2.1. Snow Water Equivalent (SWE). The primary daily SWE record was obtained from the Natural Resource Conservation Service, which has operated the SNOTEL automated network of snowpack monitoring sites in the WUS since 1978 (http://www.wcc.nrcs.usda.gov/snow/). At each SNOTEL site, the weight of snow on a liquid-filled pillow is measured hourly by a pressure sensor and converted to SWE $[16,36,37]$. The high temporal resolution and long time series of the SNOTEL record (since the late 1970s) make it uniquely suited to the primary goals of this study. Data were selected over a 35-year period (1 October 1981 through 30 September 2016) from SNOTEL sites with continuous daily records during the snow accumulation period (1 September through 30 April the following year). Overall, data from 222 SNOTEL sites located within the 6 watersheds were considered suitable. The numbers of selected SNOTEL sites in the six watersheds are listed in Table 1, and the locations of the stations are marked in Figure 1. The selected stations covered all the mountains of each watershed; thus, the snow metrics could be calculated reliably without undue interference from sampling errors and/or seasonal effects.

2.2. Streamflow. The streamflow data are available on the Internet from the National Water Information System of the USGS (http://waterdata.usgs.gov/nwis/). The stations were categorized according to the hydrologic drainage basins in the US known as hydrologic unit codes developed by the USGS [12]. Because human interventions such as reservoirs
TABLE 1: Numbers of SNOTEL and streamflow stations used in this study.

\begin{tabular}{lccccccc}
\hline & RG & UC & LC & GB & PNW & CA & Total \\
\hline SNOTEL & 12 & 39 & 15 & 54 & 92 & 10 & 222 \\
Streamflow & 43 & 63 & 51 & 54 & 209 & 41 & 461 \\
\hline
\end{tabular}

and other diversions could potentially alter the routes of river systems, the USGS maintains unimpaired streamflow stations within the Hydro-Climatic Data Network 2009 (HCDN-2009) [38]. In the site selection process of this study, these sites were chosen first. However, the number of HCDN-2009 stations is limited and their spatial distribution is uneven. Therefore, other USGS sites (added stations) were incorporated based on the following quality assurance/quality control procedure. First, manual screening was performed to remove those with incomplete daily data. Second, the watershed mean pentad anomaly streamflow of all the HCDN-2009 stations in each watershed was calculated. Then, sites that were obviously inconsistent with the HCDN-2009 stations, based on a comparison of the correlation coefficient of the pentad anomaly streamflow between each added station and the watershed mean, were discarded. This step was performed to remove any station that had been obviously influenced by anthropogenic activities. The data period was the same as for the SWE sites. The numbers of selected stations in each of the six watersheds is listed in Table 1, and the locations of the stations are marked in Figure 1. The selected streamflow stations covered nearly all the major rivers in each watershed, providing strong support for the subsequent data analysis.

2.3. Precipitation and 2- $m$ Temperature. Daily precipitation and daily mean $2-\mathrm{m}$ temperature data were obtained from 
the PRISM dataset named AN81d [39, 40]. This daily dataset, covering the conterminous US, began on 1 January 1981, and it continues to the present day, and the spatial resolution was $4 \mathrm{~km}$. To derive best estimates, this dataset uses all the station networks ingested by the PRISM Climate Group (13 station networks for temperature and 20 station networks for precipitation). Climatologically aided interpolation (detailed in Descriptions of PRISM Spatial Climate Datasets, 2015 [41]), using 1981-2010 monthly climatologies as predictor grids, was adopted to enhance the accuracy of the climate analysis. Furthermore, the precipitation dataset was created by computing an elevation-precipitation relation for all stations within a subregion, with individual stations weighted differently, and by applying that relation to a topographic basemap. In this study, the data period was the same as for SWE and streamflow. The precipitation data with $4 \mathrm{~km}$ high spatial resolution and correction for elevation were considered suitable for the requirements of precipitation system analysis over high mountain areas and for determining effective rainfall areas. The 2-m temperature data were used to classify precipitation as either rain or snow for analysis of the rainfall contribution.

\section{Methodology}

3.1. Snow Metrics. This study adopted eight snow metrics following the work of Trujillo and Molotch [25]. These metrics comprise the initial snow accumulation day and snow-free days, the peak of snow accumulation and date of the peak, the length of the snow accumulation season and the length of the snowmelt season, and the snow accumulation slope and snowmelt slope. This research focused on the relationship between long-term snow accumulation and streamflow. Therefore, the calculations for all of the metrics were based on the longest snow cover period $(>20 \mathrm{~d})$ in each water year, and short-term snow periods were neglected. The eight metrics were derived from the daily SWE data at each station. The daily SWE curve (Figure 2) for accumulation and melt seasons shows the basic metrics that can be used to characterize the snowpack dynamics at a particular station. Metrics (1) and (2) mark the days of initial snow accumulation and snow disappearance, respectively. Metrics (3) and (4) mark the peak SWE date and peak SWE value, respectively. Metrics (5) and (6) indicate the lengths of the accumulation and melt seasons, respectively. The snow accumulation slope and snow snowmelt slope are represented by the peak snow accumulation divided by the length of the snow accumulation season and by the length of the snowmelt season, respectively.

In the correlation analysis with peak streamflow, the snow state in each watershed is considered to have consistent characteristics; thus, the snow metrics are the mean values of all the SWE stations in each individual watershed.

\subsection{Lead Correlation of Snow Accumulation to Streamflow.} Because streamflow has a long-term snowpack memory, that memory could be calculated as the predictive time of the influence of snowpack on streamflow. The lead time

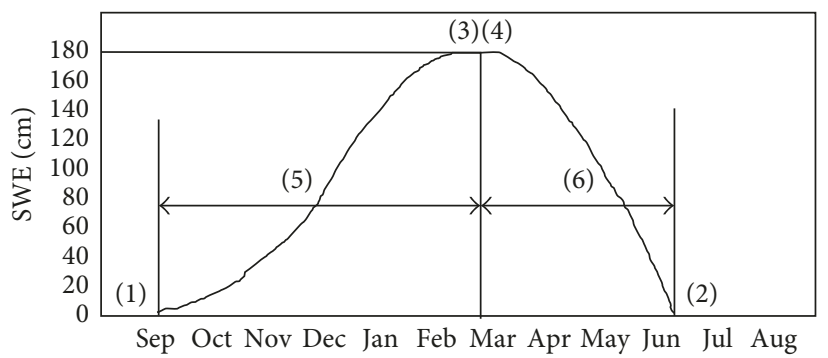

FIGURE 2: Sketch of the basic snow metrics based on the daily SWE curve. Metrics (1) and (2) mark the days of the initial snow accumulation and snow disappearance, respectively. Metrics (3) and (4) mark the peak SWE date and peak SWE value, respectively. Metrics (5) and (6) indicate the length of the accumulation and melt seasons, respectively.

(memory) was derived from the lead correlation between the long-term SWE pentad anomaly and the streamflow pentad anomaly. Here, because the study area was divided into six watersheds, it was assumed that the snow characteristics of each individual basin were uniform. The lead correlation was calculated between the basin mean long-term (i.e., 35 years) SWE pentad anomaly and the long-term streamflow pentad anomaly at each stream site in the corresponding basin. As the response time of streamflow to snowpack is different at each site, a group of correlation coefficients was calculated with lead times ranging from 0 to 73 pentads for every site. Then, the maximum correlation coefficient corresponding to the lead time was considered the predicting period for that site.

3.3. Relative Contributions of Rainfall and Snowpack. In this study, rainfall and snowpack were chosen as the principal streamflow contributors. For snowpack, snow accumulation was adopted rather than snowfall. This is because the influence of snowpack on streamflow is realized when the snow accumulated in mountainous areas is released during the spring, discounting the negligible amounts of snow that fall directly into rivers. Because it is difficult to obtain observed rainfall data, PRISM precipitation data were classified as snowfall or rainfall based on PRISM 2-m-resolution temperature data. To verify the feasibility of this method, the classified snowfall data were evaluated against SNOTEL in situ SWE data. Subsequent to data preparation, the contributions of both rainfall and snowpack to streamflow were calculated according to the following procedure.

First, it was necessary to determine the rainfall area with a direct impact on each streamflow station. As rainfall has a direct influence on streamflow, it was assumed that a change in the streamflow anomaly would have the same pattern as a change in the contributed rainfall anomaly. The rainfall area that affected each streamflow site was chosen based on the criterion that the pentad rainfall anomaly had a significant correlation with the runoff anomaly of that site during the wet season. The wet season was chosen instead of the entire year to avoid seasonal variations. The wet season, which differs among each basin, was selected based upon 


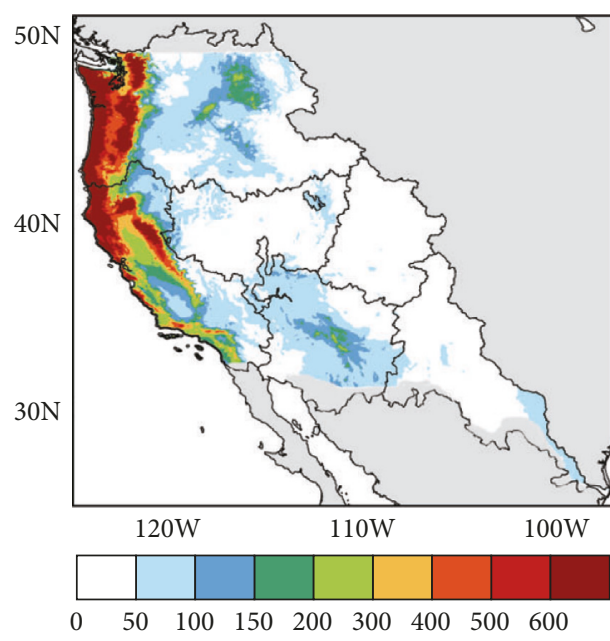

(a)

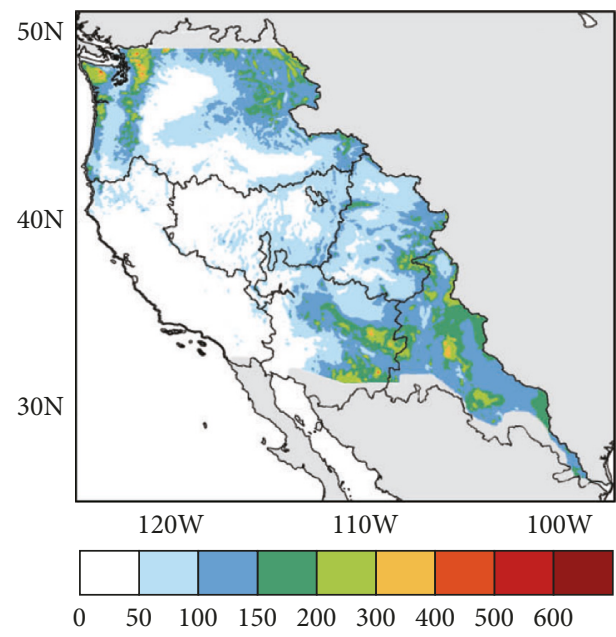

(c)

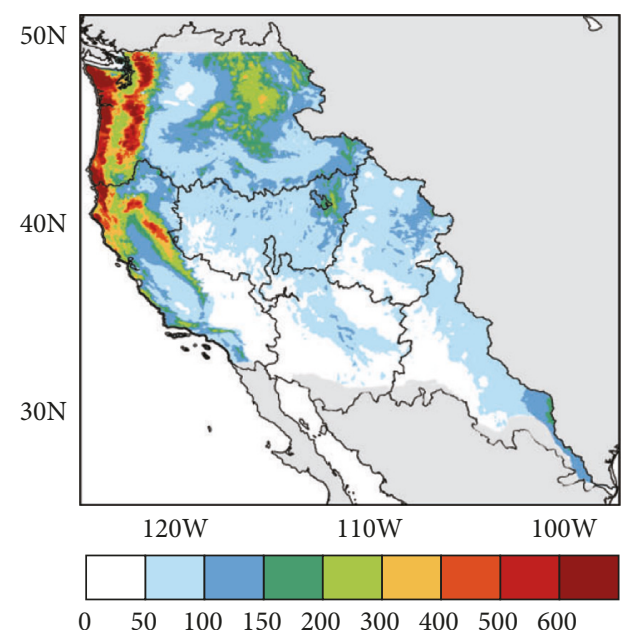

(b)

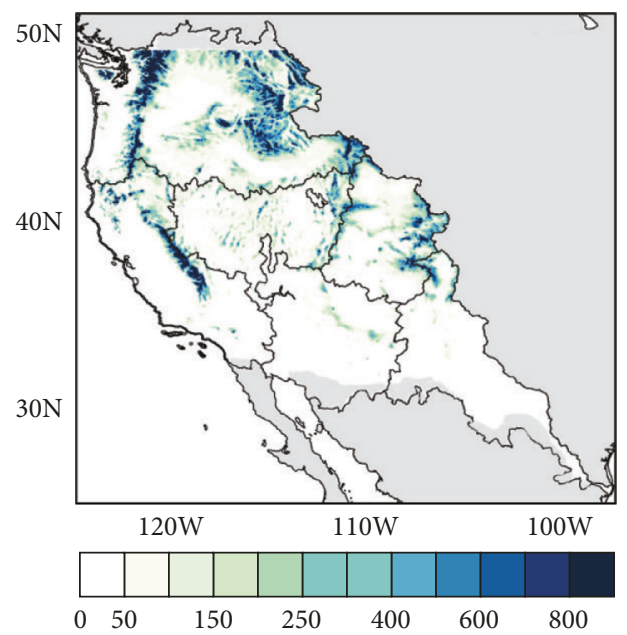

(d)

FIGURE 3: Mean precipitation during 1981-2016 (unit: mm): (a) winter mean rainfall, (b) spring mean rainfall, (c) summer mean rainfall, and (d) annual mean snowfall.

the long-term averaged seasonal variation in the rainfall (Figure 3, RG: Jul-Sep; UC: Jul-Sep; LC: Jul-Sep; GB: Mar-May; PNW: Oct-Dec; CA: Dec-Mar). The regional mean rainfall anomaly of the selected area was the effective rainfall anomaly of each station.

Second, the long-term pented rainfall and SWE anomalies at each streamflow site were normalized, and then use (1) to fit the two normalized variables into a new variable, which is called $\operatorname{comb}_{a}$.

$$
\begin{array}{r}
\operatorname{comb}_{a}(i)=a(i) \cdot \operatorname{Rain}_{a}+(100-a(i))\left(\mathrm{SWE}_{a}+\text { lead time }\right), \\
a(i)=i-1, i=1,2, \ldots, 101 .
\end{array}
$$

where $\mathrm{SWE}_{a}$ is the normalized basin mean long-term pentad SWE anomaly, Rain $a$ is the normalized long-term pentad rainfall anomaly, lead time is the highest probability of all the lead times in each basin, and $a$ is the relative contribution ratio of rainfall from 0 through 100 . The snow accumulation contribution ratio is represented as $100-a$ because only these two contributors were considered in this study.
Third, using the group of the combined array to perform the correlation with streamflow at each site in each basin, the peak correlation among the group of correlations was selected. The peak correlation corresponding to $a$ and $100-a$ represents the contribution ratio to streamflow at each station.

\section{Results}

4.1. Rain, Snow, and Streamflow in the WUS. Because streamflow variation depends largely on the precipitation system, the variation and distribution of precipitation should first be established. Two principal precipitation mechanisms affect the WUS. The first is associated with eastward-moving winter Pacific storms, which bring heavy precipitation to coastal areas and the western highlands, thereby reflecting the considerable orographic effects generated by upslope motions [42-44]. The second precipitation system is associated with subtropical summer monsoon rainfall. 


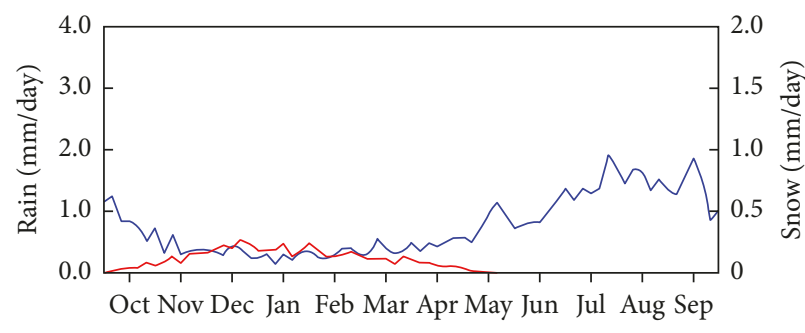

(a)

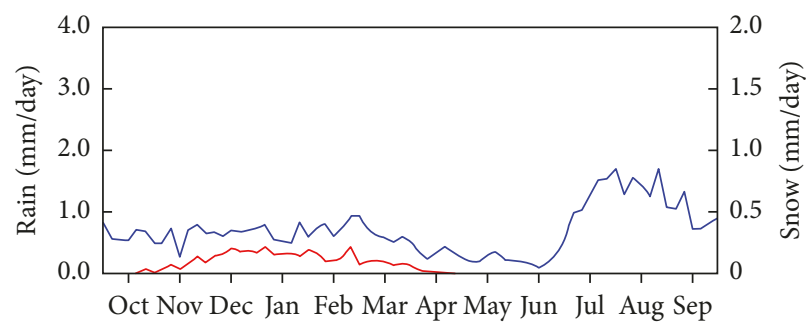

(c)

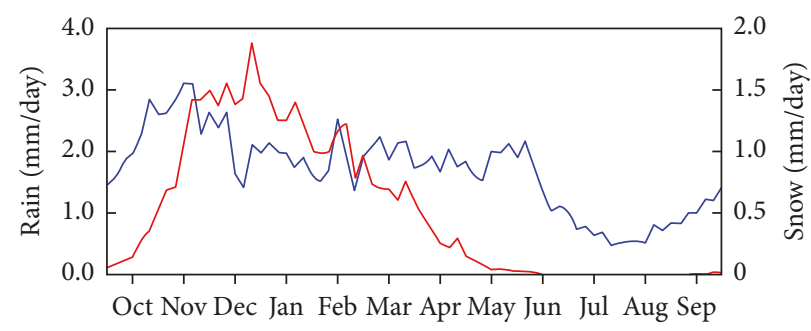

(e)

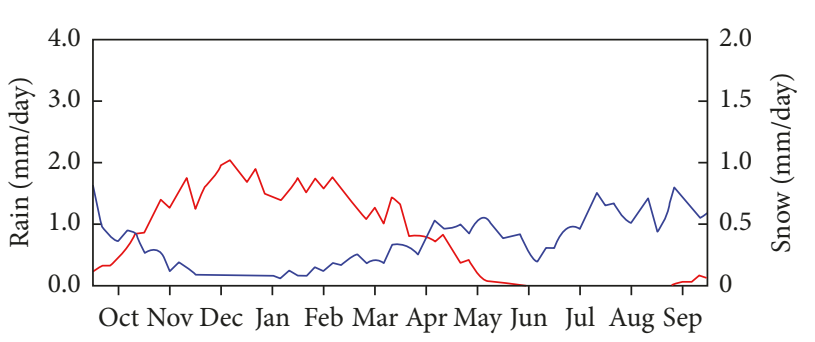

(b)

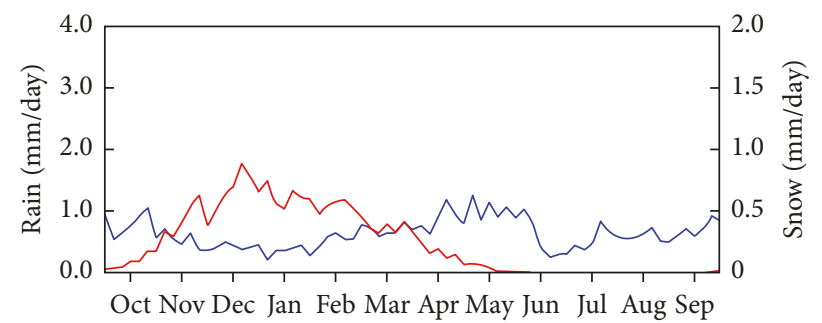

(d)

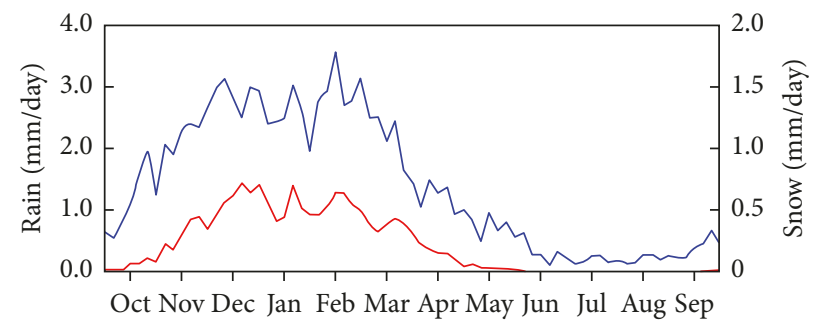

(f)

FIgure 4: Annual time series (1981-2016) of the regional mean precipitation (blue line: rain; red line: snow). Panels (a)-(f) successively represent watersheds (a) RG, (b) UC, (c) LC, (d) GB, (e) PNW, and (f) CA.

The temporal variations and distributions of seasonal rainfall and annual snow amounts over the WUS are illustrated in Figures 3 and 4. It is evident that considerable rainfall occurs during winter, particularly in the Cascade, Klamath, and Sierra Nevada mountains and over coastal areas. Compared with winter, both the amount and the area of rainfall in spring are generally diminished, but the locations of the rainfall centers remain similar. However, in the Rocky Mountains, the rainfall amount increases in spring because snowfall transfers to rainfall with rising temperatures. Summer precipitation is located primarily within the RG and LC watersheds (i.e., summer monsoon rainfall), whereas precipitation is reduced considerably in the PNW because Pacific storm systems are weaker in this season. In the WUS, snowfall generally commences at the end of autumn and it ends in early spring (Figure 4). The area of snow cover is generally concentrated within inland areas of the Cascade, Sierra Nevada, and Rocky Mountains, and the amount of snowfall increases from south to north.

Because of its low latitude, the RG basin receives the least amount of snowfall; however, its large runoff in spring suggests that snowmelt in the southern Rocky Mountains is the main source of its streamflow. The summer monsoon constitutes the primary precipitation system affecting the RG basin throughout the entire year, and it provides a major source of summer runoff (Figures 4(a) and 5(a)). Most of the
UC basin lies within the southern Rocky Mountains. The considerable accumulation of wintertime snow therein indicates that subsequent snowmelt provides abundant water for spring runoff; thus, the period of high flow, during which time the flow is substantially higher than during the other months, is concentrated during May-July (Figures 4(b) and $5(b))$. Streamflow in the LC basin is similar to that in the RG basin. The spring streamflow in both basins is fed primarily by snowmelt from the southern Rocky Mountains. However, because the Rocky Mountains are located further to the south than in the RG basin, the period of snowfall is short and the amount of accumulation is low; therefore, the spring streamflow contributed by snowmelt is less prominent compared with the other seasons. Furthermore, the contributions to runoff from both winter and summer rainfall produce a curve of seasonal runoff variations with reasonably gentle features (Figures 4(c) and 5(c)). The GB watershed exhibits a midlatitude desert climate; the amount of rainfall in this basin is the least among all of the studied watersheds. The GB is bordered by the Sierra Nevada range to the west and the Wasatch and Uinta Mountains to the east. Therefore, its streamflow is supplied primarily by snowmelt from these two mountain ranges (Figures $4(\mathrm{~d})$ and 5(d)). The PNW has a largely marine oceanic climate with considerable rainfall throughout the entire year, except during the summer. Further to the east, it has a semiarid-steppe 


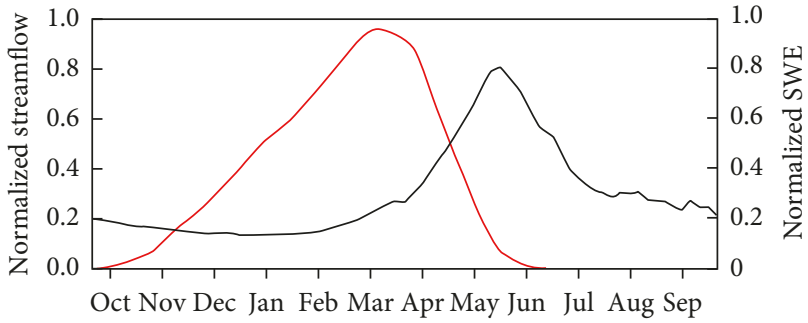

(a)

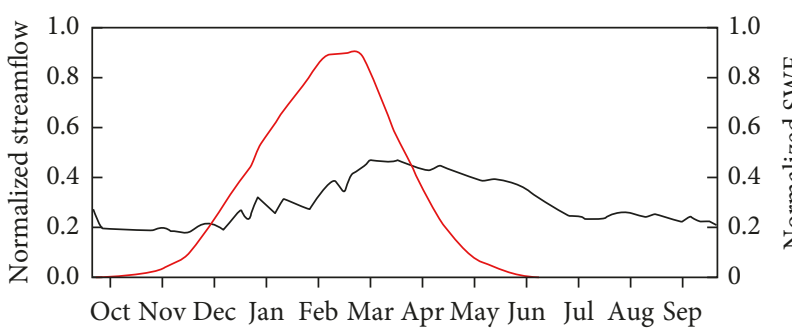

(c)

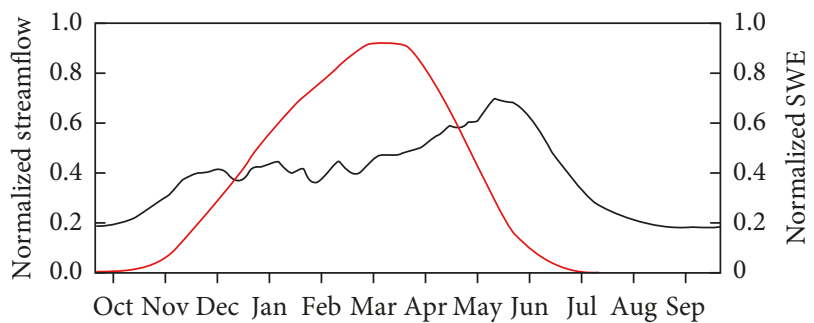

(e)

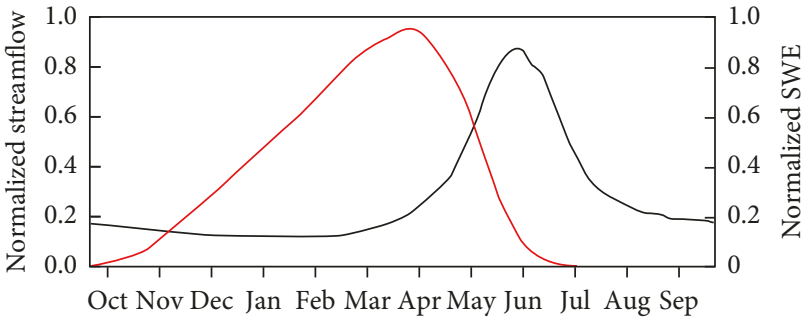

(b)

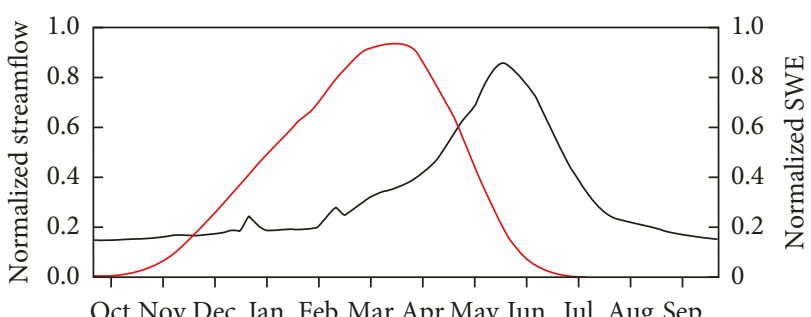

(d)

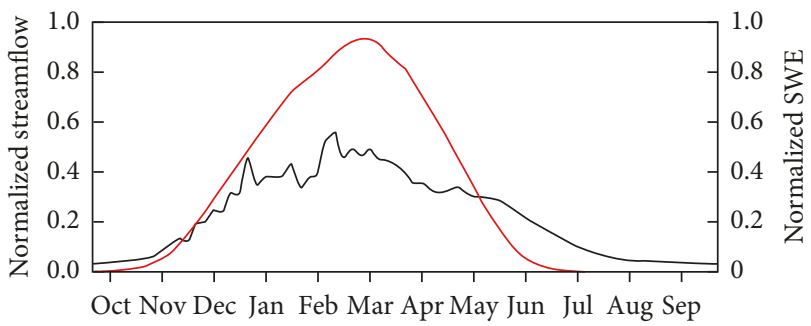

(f)

FIGURE 5: Annual time series (1981-2016) of the normalized SWE and streamflow (black line: streamflow; red line: SWE). Panels (a)-(f) successively represent watersheds (a) RG, (b) UC, (c) LC, (d) GB, (e) PNW, and (f) CA.

climate. Snow accumulation over the northern and central parts of the Rocky Mountains stores vast quantities of water for the PNW. Thus, based on winter rainfall and spring snowmelt, the annual streamflow variations display a characteristically sustained increase from the early winter to the end of the spring (Figures 4(e) and 5(e)). The Mediterranean climate of the CA basin is reflected by cool, wet winters and hot, dry summers. This area has more precipitation in winter and spring, which is the main source of streamflow; thus, runoff and precipitation show synchronized seasonal variations (Figures 4(f) and 5(f)).

Although the basins of the WUS exhibit a certain degree of consistency in terms of their hydroclimatic situations, the seasonal variations in both precipitation and streamflow reveal that each basin does have its own characteristics. Therefore, to enhance an understanding of the hydroclimatic situation of the WUS, the relationships between the precipitation systems and streamflow must be explored for each individual basin.

4.2. Correlation between Snow Metrics and Streamflow Peak. Because streamflow has a short response time to rainfall, only snowfall was considered in this analysis. To obtain meaningful seasonal predictors of runoff, the relationships to runoff of eight snow metrics (detailed in Section 3) were explored. Based on the work of Trujillo and Molotch [25], the selected metrics have different nonlinear relationships in the different regions of WUS (i.e., maritime climate, intermountain climate, and continental climate); thus, the relationships between the snow metrics and the runoff peak can be discussed independently. The focus of this study was on the relationships between the snow metrics and the runoff in each of the six individual watersheds. Therefore, the snow metrics were taken as the average values from all of the SWE sites in each watershed. The 95th percentile of the annual streamflow, which is strongly related to the wet season streamflow amount and flood disasters, was used to perform the correlation for the streamflow metric.

Figure 6 shows that each snow metric has different characteristics in each region. Except for the initial snow accumulation day, which primarily has a negative correlation with the peak streamflow, all of the other metrics have positive correlations. The negative correlations displayed in Figure 6(a) indicate that an earlier onset of snow accumulation corresponds to a higher peak streamflow. This is intuitively correct because an early occurrence of snow would generally correspond to deeper snowpack, which would cause greater streamflow during the snowmelt season. However, this correlation is not significant for all of the six basins, that is, this metric is relevant only in the northern RG, UC, and GB watersheds. Among the remaining metrics, 


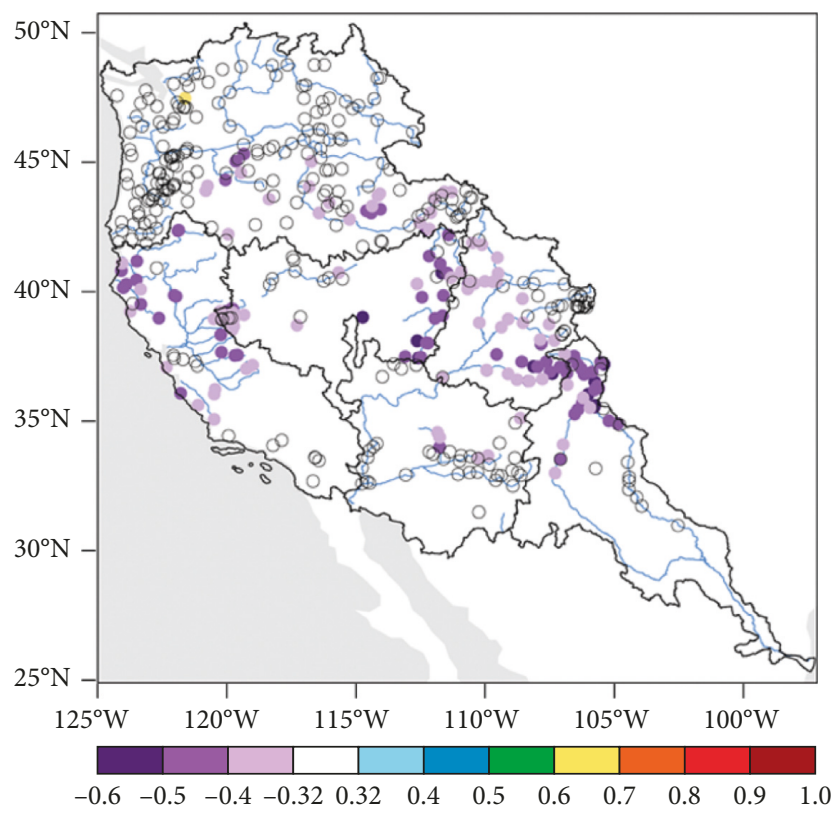

(a)

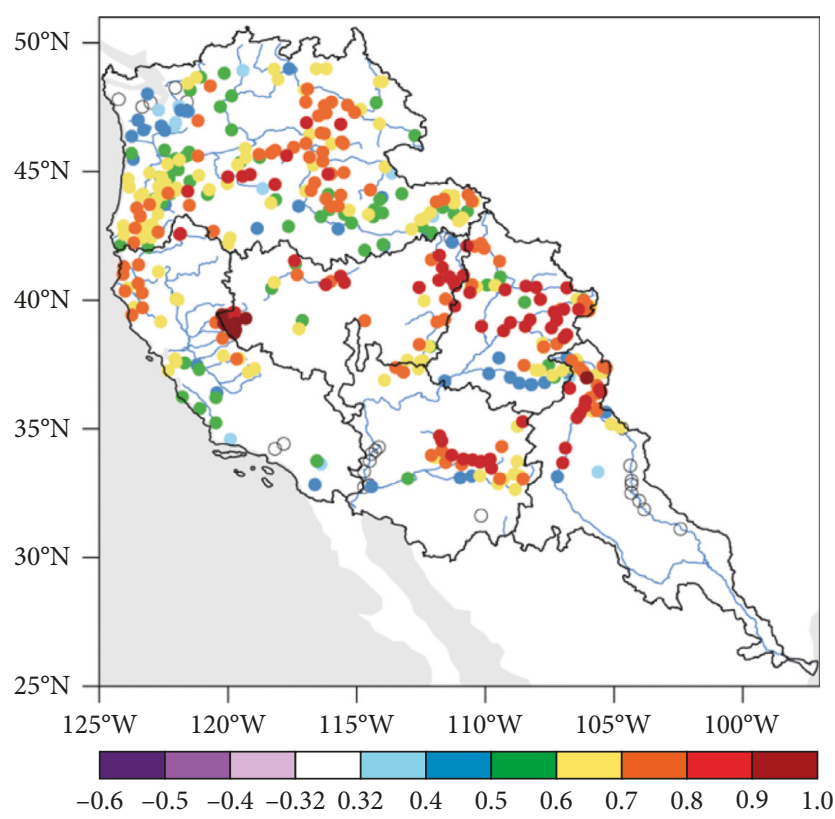

(c)

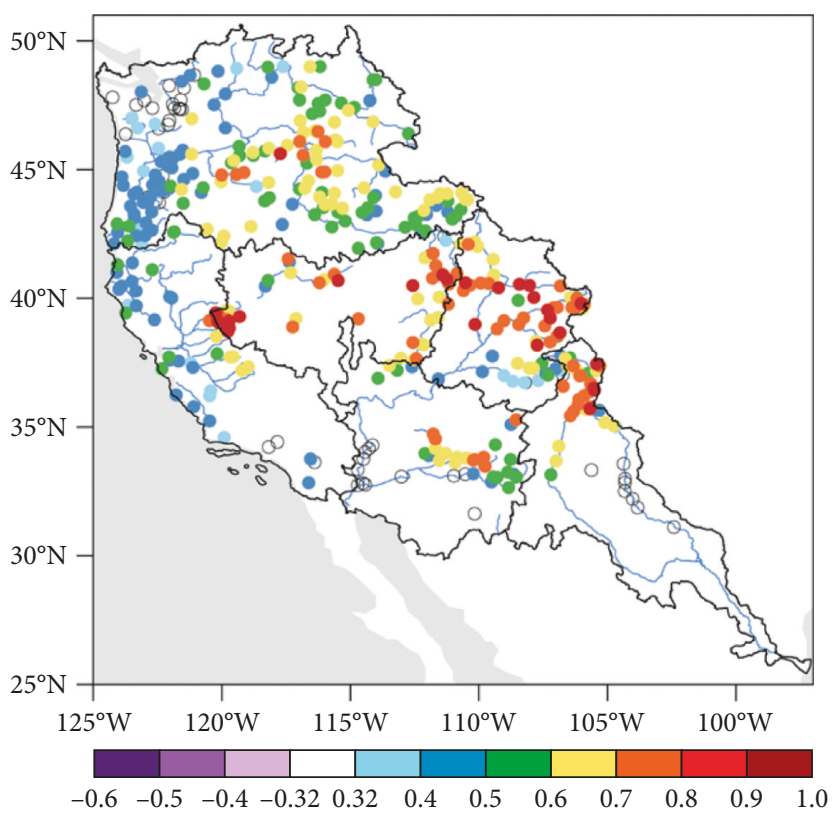

(b)

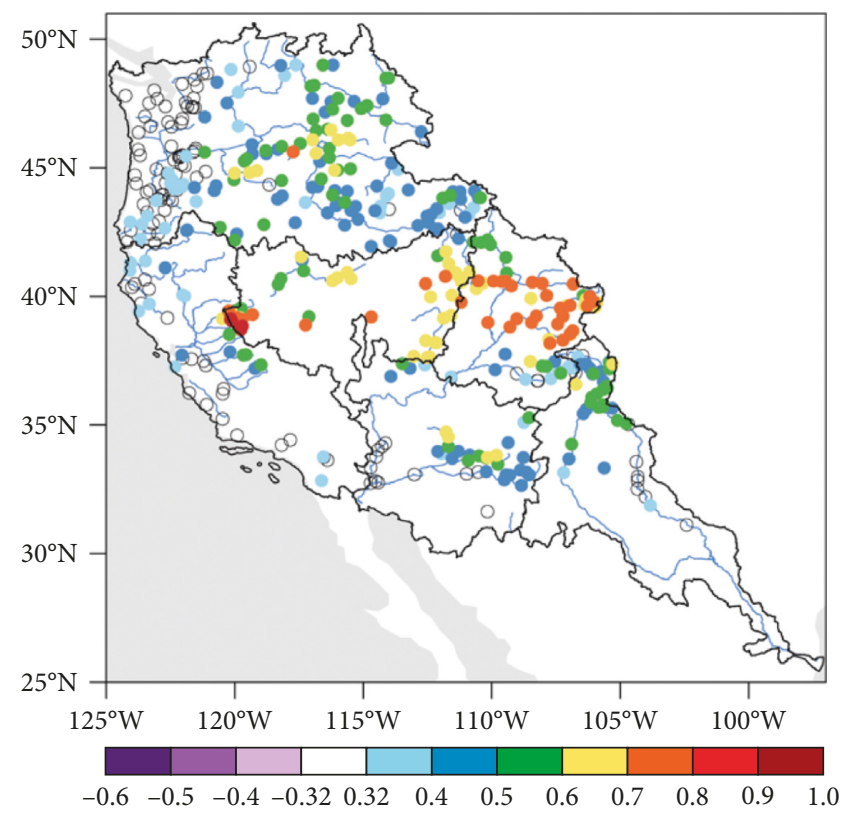

(d)

Figure 6: Continued. 


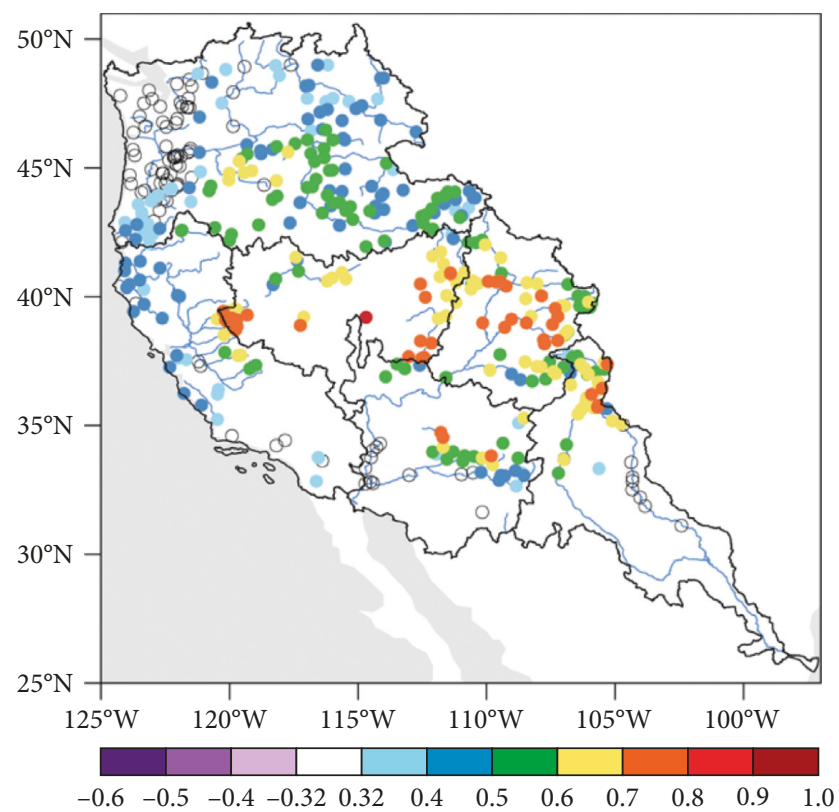

(e)

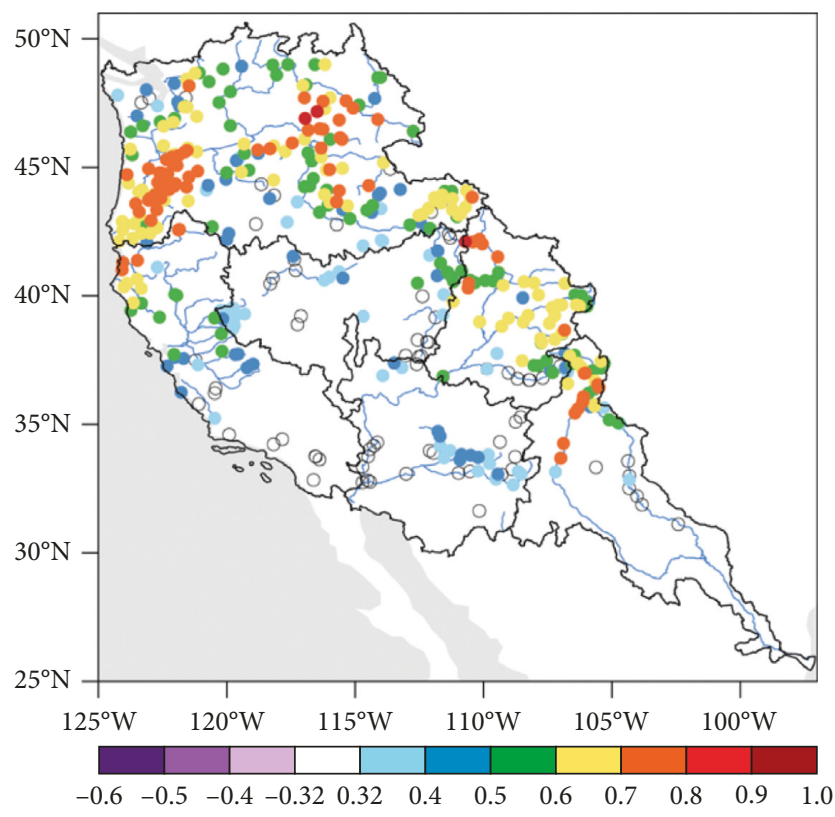

(g)

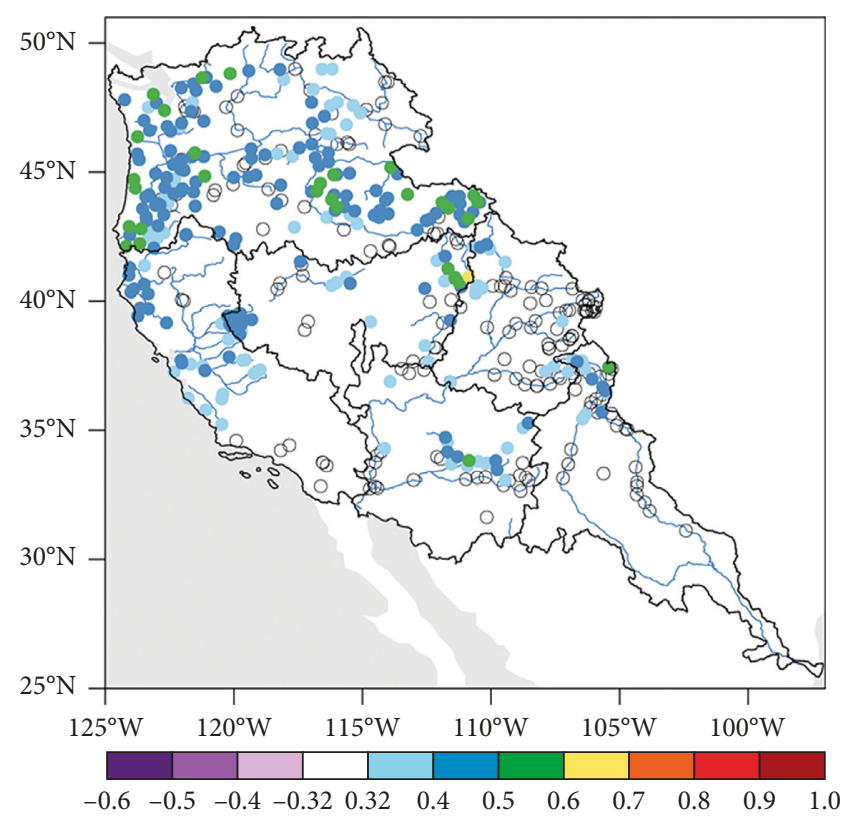

(f)

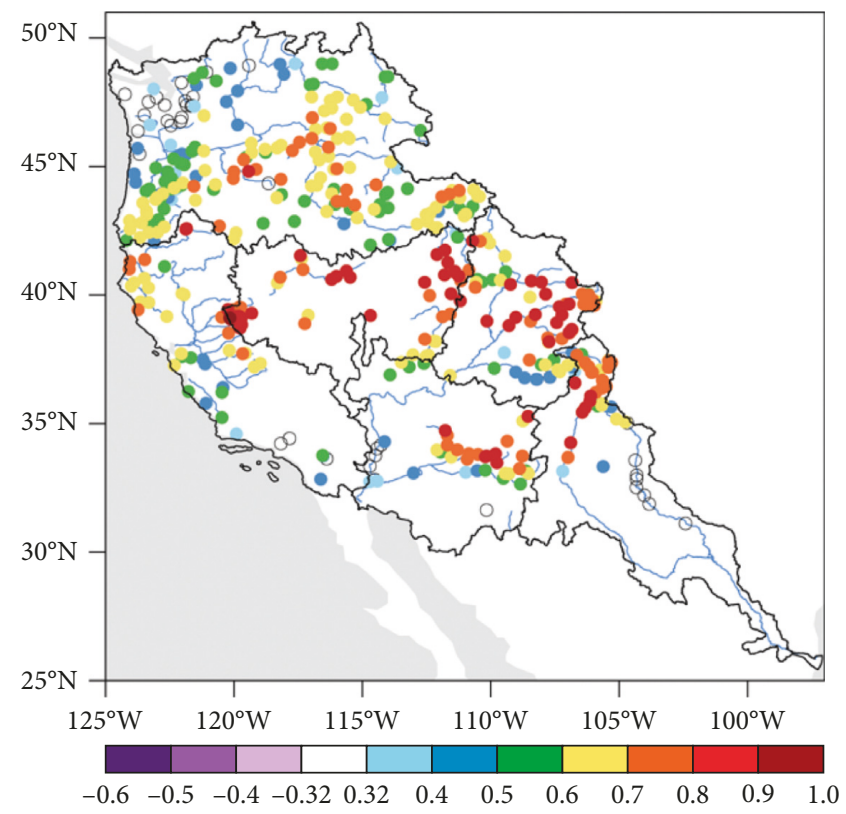

(h)

FiguRE 6: Distributions of the correlation coefficients between the snow metrics and peak streamflow in each watershed (1981-2016). Panels (a)-(h) represent different snow metrics: (a) the initial snow accumulation day, (b) snow-free day, (c) peak SWE value, (d) peak SWE day, (e) length of snow accumulation season, (f) length of snow melting season, (g) snow accumulation slope, and (h) snowmelt slope. Circles represent stations that did not pass the $95 \%$ significance test.

the peak of snow accumulation, the snow-free days, and the snowmelt slope all demonstrate strong positive correlations with the peak runoff (i.e., considerable snow accumulation, late snow disappearance, and rapid snowmelt all correspond to a high peak streamflow), followed by the date of peak accumulation, the length of snow accumulation, and the snow accumulation slope. The distribution of these correlations (Figure 6) shows that most of the metrics are strongest in the UC and GB watersheds. This is because water storage is dominated by snowmelt in these areas; thus, the snow metrics are more informative. In addition, both the RG and the LC basins are located in the lower latitudes of the WUS; therefore, they receive less snow than the other basins (Figures 3 and 4), and their downstream runoff is affected principally by rainfall. Those runoff sites that have strong correlations with the snow metrics are concentrated in the upstream areas near the mountains. It is noteworthy that in the coastal areas of the PNW and CA basins, although runoff 
is dependent primarily on winter rainfall, these results do show certain correlations with the snow metrics. This is because both rainfall and snowfall in these two basins are caused by the same weather systems; thus, they appear almost synchronized, which means that these snow metrics appear to have certain correlations that represent the regional rainfall characteristics. In conclusion, the peak of snowfall accumulation, the snow-free days, and the snow snowmelt slope could be used as the principal metrics for predicting the peak value of the runoff throughout the WUS, especially in the inland mountain areas. Among the three most significant metrics, the peak of snowfall accumulation demonstrated the strongest correlation with the peak streamflow. This result shows that snow accumulation could be used to quantify the forecast period of runoff variations.

\subsection{Lead Correlation of Snow Accumulation and Streamflow.} This analysis explores the forecasting effect of snow accumulation on runoff based on the long-term pentad anomaly of SWE and runoff (detailed in Section 3). Figure 7 shows that almost all runoff sites passed the 95\% significance test and most have strong correlation. The lead correlation between SWE and streamflow was examined from 0 through 14 pentads. Overall, in the inland mountains, the lead time is more than 4 pentads, while in coastal areas, the lead time is $0-1$ pentads.

Among the six watersheds, the UC and GB basin show the longest snow memory in terms of the runoff, that is, generally 4-10 pentads. Snowfall in the RG basin is concentrated largely over the southern Rocky Mountains, which is where the source of the Rio Grande River (the westernmost of the two main rivers in the RG basin) is located. Therefore, the runoff into the river is derived primarily from snowmelt, and the river shows a lead correlation of 5-7 pentads. In contrast, the Pecos River, which is located on the eastern side of the RG basin, originates from the southern edge of the Rocky Mountains. Thus, summer rain has much greater impact than snowmelt on the runoff of this river, and no strong correlation with SWE is observed. In the LC basin, the response time of snow to runoff is short, and most runoff sites do not have a strong correlation with snowmelt. Because the snow storage in the LC basin is small, the snowmelt period is short compared with those of other watersheds, and most of the water resources in this basin are derived from summer monsoon rainfall. The occurrences of rainfall and snowfall during the winter are highly consistent, indicating that they are both caused by the same weather systems, that is, mountainous areas receive snow while areas at lower elevations receive rain. The response of the runoff to rainfall is very short, that is why the lead correlation in the basin is just 0-1 pentads showed in Figure 7. The coastal area of the PNW shows a short lead time and a low correlation coefficient. This is because eastward-moving Pacific storm systems during the winter generate considerable rainfall in front of the mountainous areas and abundant snowfall at high elevations, that is, the rainfall and snowfall in this basin are generated by the same weather systems, as discussed for the LC basin. The amount of precipitation over the eastern area of the PNW is much smaller than that over the coastal

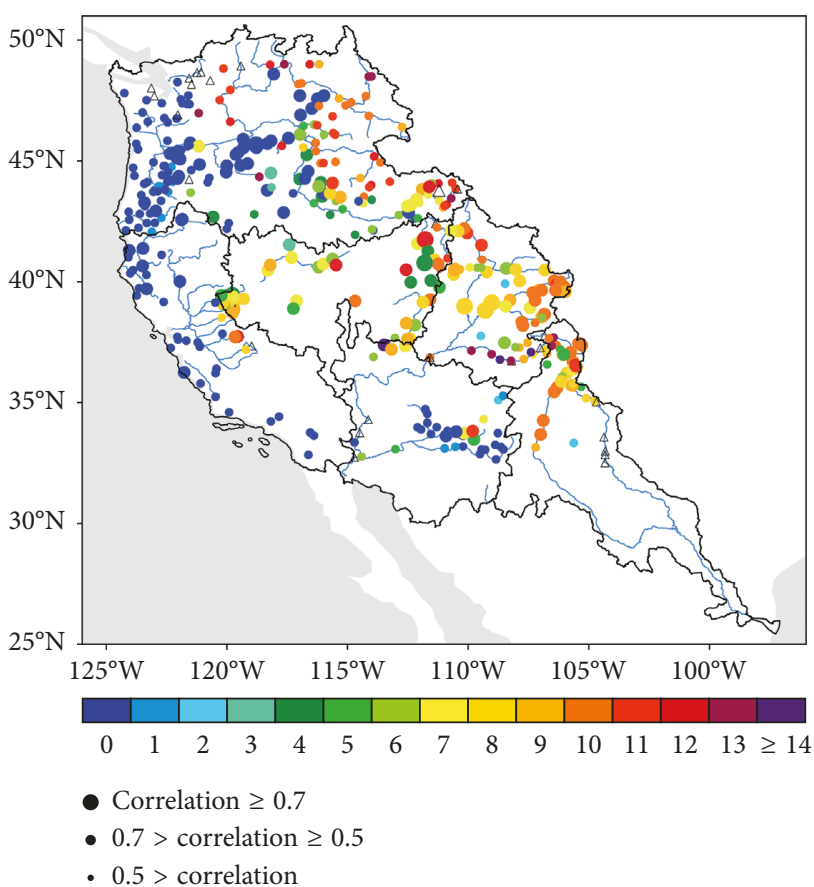

Figure 7: Distribution of the peak lead time and correlation coefficient between the snow anomaly and streamflow anomaly (unit: pentad). Hollow triangles represent stations that did not pass the 95\% significance test.

areas. Runoff in the eastern PNW is caused predominantly by snowmelt; thus, Figure 7 shows that this region has a significantly longer lead time correlation than the western part. In the CA basin, except for the eastern Sierra Nevada range, where snow contributes considerably to runoff and causes a long lead correlation, most of the regional runoff is affected by rainfall with characteristics similar to the rainfall in the western PNW. This results in a lead correlation of 0-1 pentads with the SWE; however, the short lead correlation simply reflects the relationship between rainfall and runoff.

In summary, these findings provide a reasonably reliable basis for streamflow predictions over the WUS. It is also established that the lead times calculated using the pentad mean data (not show here) are longer than those obtained using the pentad anomaly data. This is because the lead time of the former one represents the period between the snow peak and the runoff peak, whereas the pentad anomaly reflects the relationship between changes in snow accumulation during the snowmelt period and the runoff anomaly. Thus, the lead time of the latter is shorter than the former. Furthermore, the above analysis highlights some problems. In some areas where rainfall dominates over runoff, the lead correlation reflects the relationship of streamflow with rainfall rather than with snow. Therefore, the relative contributions from both rainfall and snow accumulation at each runoff site must be combined to perform runoff anomaly predictions.

4.4. Relative Contributions of Rainfall and Snowmelt. To obtain predictions with greater accuracy at each streamflow site, the relative contributions from both rainfall and snowpack to each streamflow station were calculated. The 


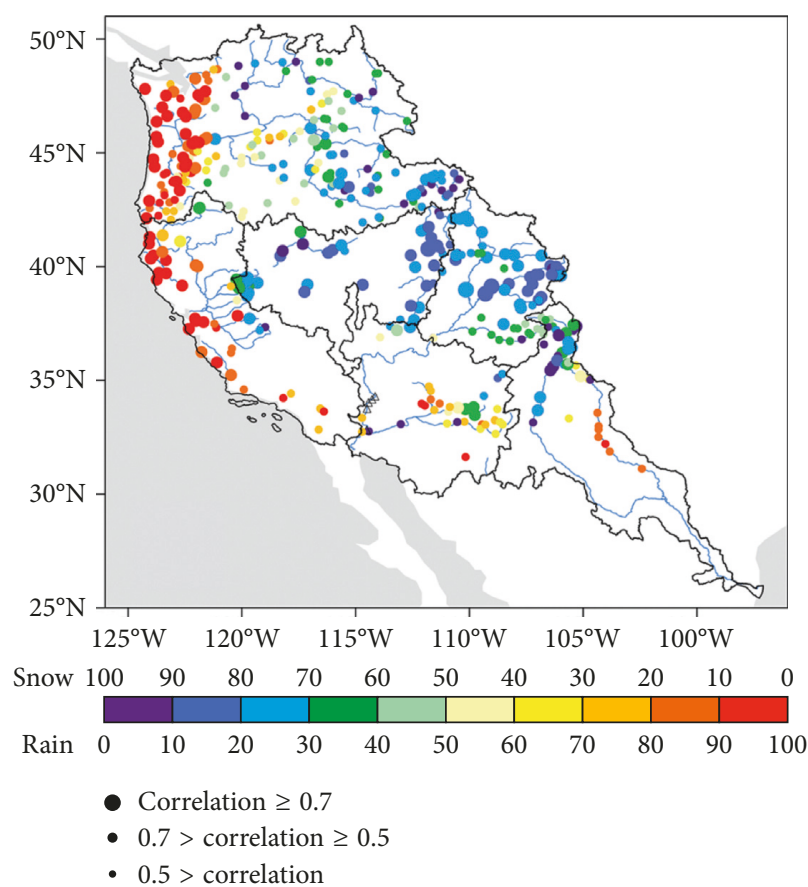

(a)

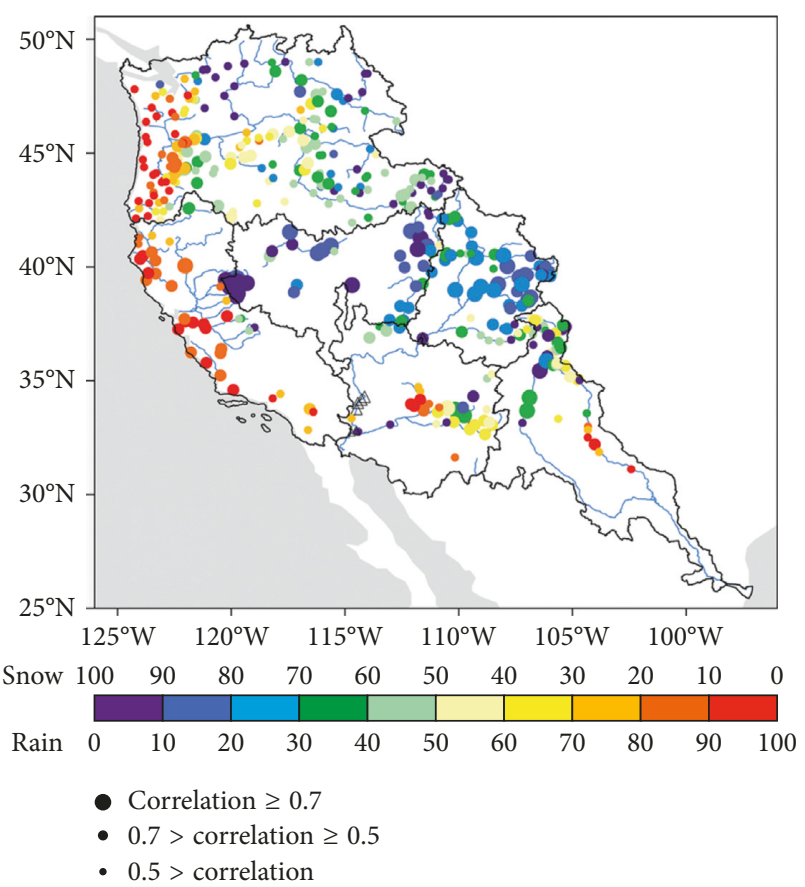

(b)

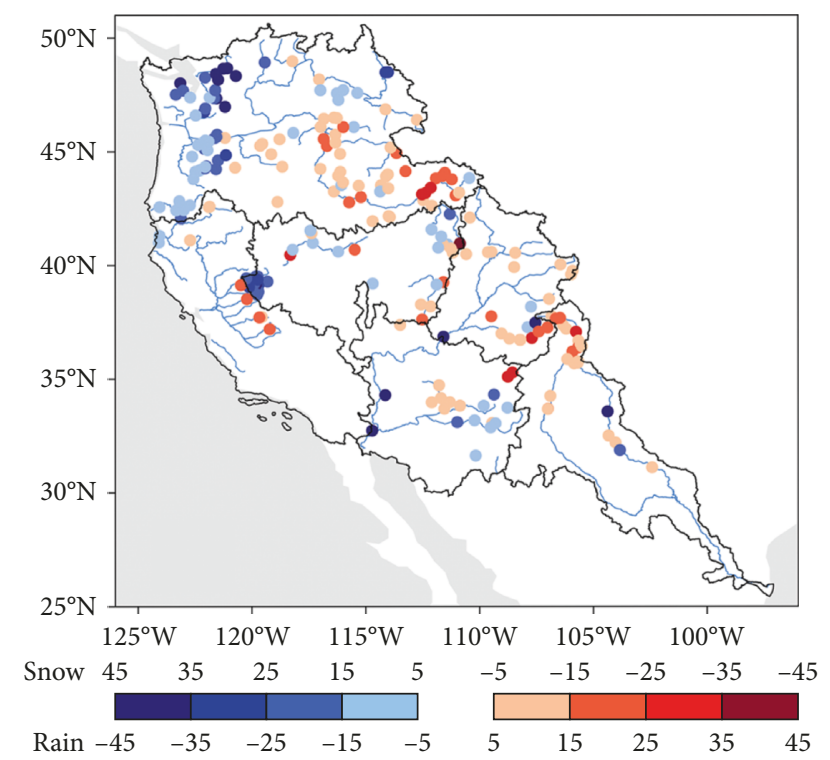

(c)

FIGURE 8: Distributions of the relative contributions of rainfall and snowfall to each streamflow station (unit: \%): (a) annual contribution, (b) high-flow season contribution, and (c) difference between the high-flow season and annual contributions (i.e., high-flow season-annual). Hollow triangles represent stations that did not pass the $95 \%$ significance test.

rainfall and snowfall areas and their ratio were not used to directly distinguish between $f_{\text {rain }}$ and $f_{\text {snow }}$ for two reasons. First, the impact of the snowmelt area is greater than that of the snow cover area, that is, a site located in a rainfall area might receive a greater contribution from snowmelt than from rainfall. Second, the response of runoff to rainfall is short, while snowmelt has a longer runoff memory with a contribution that is mainly in the spring. Therefore, for a particular runoff site, if the rainfall season and snowmelt seasons occur at different times, the site will receive different water resources during different seasons. Conversely, if the wet and snowmelt seasons occur at the same time, the site will receive contributions from both resources. Therefore, this study adopted a new method (detailed in Section 3) to calculate the annual $f_{\text {rain }}$ and $f_{\text {snow }}$ values and to determine the relative contribution rates for the entire year and the high-flow season (i.e., the wet season).

The geographic distribution of the annual relative contributions of rainfall and snowmelt presented in Figure 8 (a) shows that values of $f_{\text {snow }}>50 \%$ are distributed primarily 
in the UC, GB, eastern PNW, and northern RG basins. In these areas, the upper streams in the mountains receive greater contributions from snow accumulation, that is, up to $70 \%$ or more. Based on the terrain elevation and distribution of precipitation systems (Figures 1 and 3), it is evident that these areas are high mountainous regions that receive large amounts of snowfall. Snowpack provides abundant water storage in these large areas. In the coastal areas of the PNW and CA basins, the value of $f_{\text {rain }}$ is $>50 \%$. Despite the large amounts of snowfall received by the Cascade Mountains and the Sierra Nevada, the contributions from rainfall still dominate these areas. For the LC basin, monsoon rainfall provides a greater contribution to streamflow than snowmelt; thus, the streamflow situation in the LC basin is dominated by rainfall.

Runoff variations are an important indicator for local hydrological disasters and agricultural irrigation. Of the entire year, the high-flow season is the most crucial period for early hydrological warnings. Thus, based on Figure 5, three consecutive months with high flow were selected as the wet season for each of the six basins (RG: Apr-Jun, UC: May-Jul, LC: Mar-May, GB: Apr-Jun, PNW: Apr-Jun, and CA: Feb-Apr). Figure 8(b) shows that the distribution of relative contributions in the high-flow season is similar to the annual distribution (Figure $8(\mathrm{a})$ ), that is, rainfall dominates the coastal areas and snowmelt dominates the inner mountain areas. However, some differences between the annual and high-flow season $f_{\text {rain }}$ are shown in Figure 8(c). For example, $f_{\text {rain }}$ is reduced in the area of the Cascade Mountains in the PNW, while it is increased in the southeastern PNW. This is because the amount of rainfall over the Cascade Mountains is diminished during the high-flow season of this basin (Figure 3); thus, snowmelt becomes comparatively more prominent. The southeastern PNW experiences its heaviest rainfall during the high-flow period (Figure 3); thus, the value of $f_{\text {rain }}$ is increased to $5 \%-25 \%$. For the southern UC and northern RG basins, the contribution from rainfall is increased; alternatively, it could be considered a reduction of the snowmelt contribution. This is because the high-flow period also corresponds to the beginning of the wet season; therefore, the contribution rate of rainfall becomes more prominent. In summary, the relative contributions of rainfall and snowmelt to the runoff could support runoff predictions and could help produce seasonal runoff forecasts that would be more accurate in combination with the lead time results from the previous section.

\section{Conclusions}

Runoff is affected by many factors, such as the precipitation, soil state, land surface state, and water use. However, snow accumulation and rainfall both constitute important factors with direct impacts on the regional water supply of the WUS. Based on statistical analyses of long-term hydroclimatic data from each watershed, the predictive contributions from both rainfall and snowmelt to streamflow variations were investigated. First, the hydroclimatic characteristics of each basin were summarized in terms of the seasonal rainfall, snow, and runoff variations. Determining the basin-independent features of runoff that affect the rainfall and snow contributions made it possible to establish numerous runoff forecasting factors. Second, eight snow metrics were selected based on variations in the snow accumulation. Among all of the variables, the peak of snow accumulation, snow-free days, and snow snowmelt slope all have strong correlations with the peak runoff. Over the entire WUS, the correlations among the metrics were stronger in inland regions compared with coastal areas. Thus, these strong significant factors could be used as primary predictors for the runoff amounts during the wet season since the peak streamflow also represents the state of the high-flow season. Meanwhile, it was found that the variations in the snow accumulation anomaly exhibited a leading correlation with the runoff anomaly. This means that the streamflow prediction time based on the snow accumulation could be quantified in advance. Third, the leading relationship between snow and streamflow was analyzed, the results of which showed a lead time ranging from 0 to 14 pentads. Overall, the lead time exceeded 4 pentads in the inland mountain regions, while it was $0-1$ pentads in the coastal areas. Because of the considerable impact of snowmelt on the runoff in the UC, GB, and eastern PNW basins, the snow pentad anomaly in these areas had a 4-10 pentad lead period. In comparison, the LC, western PNW, and CA basins had short lead times largely representative of the rainfall effect. This is because their streamflows were affected primarily by rainfall and because the rainfall and snowfall therein generally occurred simultaneously. Finally, based on the pentad anomaly lead time findings, the relative contributions from both snowmelt and rainfall to the runoff at each site in each basin were analyzed. It was found that the UC and GB basins are snow-dominated areas, in which the $f_{\text {snow }}$ was greater than $f_{\text {rain. }}$. The $f_{\text {snow }}$ was the greatest in the northern RG and eastern PNW watersheds, whereas $f_{\text {rain }}$ was the greatest in the other parts of these two basins. The greatest contributions in the LC and CA basins were largely from rainfall. It was found that the contribution rate during the wet period was slightly different from the annual rate, that is, the snowmelt contribution increased in the western PWN while the rainfall contributions increased in the southeastern PWN, southern UC, and northern RG basins. In conclusion, quantitative and qualitative analyses regarding runoff predictions for the studied watersheds of the WUS constitute an important reference for hydrological management and will be useful in the evaluation and improvement of hydrological and climate models.

\section{Discussion}

This research explored the predictability of runoff in the WUS; however, scope remains for further study. (1) In this study, for the discussion of the relationship at each runoff station in each basin, the snow state in each basin was based on the average at all snow sites. However, for large watersheds, for example, the PNW, the in situ data were distributed in different mountain areas with different snow factor characteristics; thus, the method of averaging would cause some bias. In future work, subbasins will be defined to reduce this deviation. (2) When considering the contribution rates to runoff, data limitations restricted the discussion 
to just rainfall and snow. In fact, runoff is affected by many other factors such as evaporation, soil state, and groundwater. In future research, these factors will be taken into consideration. However, the findings of this study have value regarding the seasonal prediction of runoff, and they could serve as a basis for future research and model testing.

\section{Data Availability}

The data used to support the findings of this study are available from the corresponding author upon request.

\section{Conflicts of Interest}

The authors declare that they have no conflicts of interest.

\section{Acknowledgments}

The authors thank James Buxton, MSc, from Liwen Bianji, Edanz Group China (http://www.liwenbianji.cn./ac), for editing the English text of this manuscript. This research was supported by National construction of high-quality University projects of graduates and National Natural Science Foundation of China (41590874, 41675107, and 41775081).

\section{References}

[1] D. W. Pierce, T. P. Barnett, H. G. Hidalgo, T. Das, C. Bonfils, and B. D. Santer, "Attribution of declining Western U.S. Snowpack to human effects," Journal of Climate, vol. 21, no. 23, pp. 6425-6444, 2008.

[2] P. Z. Klos, T. E. Link, and J. T. Abatzoglou, "Extent of the rainsnow transition zone in the Western U.S. under historic and projected climate," Geophysical Research Letters, vol. 41, no. 13, pp. 4560-4568, 2014.

[3] J. A. Johnstone, "A quasi-biennial signal in Western US hydroclimate and its global teleconnections," Climate Dynamics, vol. 36, no. 3-4, pp. 663-680, 2011.

[4] J. T. Abatzoglou, "Influence of the PNA on declining mountain snowpack in the Western United States," International Journal of Climatology, vol. 31, no. 8, pp. 11351142, 2011.

[5] H. Chang and I. W. Jung, "Spatial and temporal changes in runoff caused by climate change in a complex large river basin in Oregon," Journal of Hydrology, vol. 388, no. 3-4, pp. 186-207, 2010.

[6] D. W. Clow, "Changes in the timing of snowmelt and streamflow in Colorado: a response to recent warming," Journal of Climate, vol. 23, no. 9, pp. 2293-2306, 2010.

[7] M. Ashfaq, S. Ghosh, S. C. Kao et al., "Near-term acceleration of hydroclimatic change in the Western U.S.," Journal of Geophysical Research Atmospheres, vol. 118, no. 19, pp. 10676-10693, 2013.

[8] N. Water, N. Resources, and C. Service, "A recent increase in Western US streamflow variability and persistence," Journal of Hydrometeorology, vol. 6, no. 2, pp. 173-179, 2005.

[9] J. T. Abatzoglou and C. Kolden, "Climate change in Western US deserts: potential for increased wildfire and invasive annual grasses," Rangeland Ecology \& Management, vol. 64, no. 5, pp. 471-478, 2011.

[10] D. Li, M. L. Wrzesien, M. Durand, J. Adam, and D. P. Lettenmaier, "How much runoff originates as snow in the Western United States, and how will that change in the future?," Geophysical Research Letters, vol. 44, no. 12, pp. 6163-6172, 2017.

[11] A. Kalra, S. Ahmad, and A. Nayak, "Increasing streamflow forecast lead time for snowmelt-driven catchment based on large-scale climate patterns," Advances in Water Resources, vol. 53, pp. 150-162, 2013.

[12] A. Kalra, T. C. Piechota, R. Davies, and G. A. Tootle, "Changes in U.S. streamflow and Western U.S. snowpack," Journal of Hydrologic Engineering, vol. 13, no. 3, pp. 156-163, 2008.

[13] A. Kalra and S. Ahmad, "Estimating annual precipitation for the Colorado River Basin using oceanic-atmospheric oscillations," Water Resources Research, vol. 48, no. 6, article W06527, 2012.

[14] A. Nayak, D. Marks, D. G. Chandler, and A. Winstral, "Modeling inter-annual variability in snowcover development and melt for semi-arid mountain catchment," Journal of Hydrologic Engineering, vol. 17, no. 1, pp. 74-84, 2012.

[15] T. Hunter, G. A. Tootle, and T. C. Piechota, "Oceanicatmospheric variability and western US snowfall," Geophysical Research Letters, vol. 33, no. 13, article L13706, 2006.

[16] N. Knowles, M. D. Dettinger, and D. R. Cayan, "Trends in snowfall versus rainfall in the western United States," Journal of Climate, vol. 19, no. 18, pp. 4545-4559, 2006.

[17] D. W. Clow, L. Nanus, K. L. Verdin, and J. Schmidt, "Evaluation of SNODAS snow depth and snow water equivalent estimates for the Colorado Rocky Mountains, USA," $\mathrm{Hy}$ drological Processes, vol. 26, no. 17, pp. 2583-2591, 2012.

[18] A. Harpold, P. Brooks, S. Rajagopal, I. Heidbuchel, A. Jardine, and C. Stielstra, "Changes in snowpack accumulation and ablation in the intermountain west," Water Resources Research, vol. 48, no. 11, article W11501, 2012.

[19] A. Harpold and N. P. Molotch, "Sensitivity of soil water availability to changing snowmelt timing in the western U.S.," Geophysical Research Letters, vol. 42, no. 19, pp. 8011-8020, 2015.

[20] T. B. Barnhart, N. P. Molotch, B. Livneh, A. A. Harpold, J. F. Knowles, and D. Schneider, "Snowmelt rate dictates streamflow," Geophysical Research Letters, vol. 43, no. 15, pp. 8006-8016, 2016.

[21] A. F. Hamlet, P. W. Mote, and M. P. Clark, "Twentiethcentury trends in runoff, evapotranspiration, and soil moisture in the western United States," Journal of Climate, vol. 20, no. 8, pp. 1468-1486, 2007.

[22] I. T. Stewart, D. R. Cayan, and M. D. Dettinger, "Changes toward earlier streamflow timing across Western North America," Journal of Climate, vol. 18, no. 8, pp. 1136-1155, 2005.

[23] A. E. Jeton, M. D. Dettinger, and J. Smith, Potential Effects of Climate Change on Streamflow, Eastern and Western Slopes of the Sierra Nevada, California and Nevada, United States Geological Survey, Sacramento, CA, USA, 1996.

[24] E. Bosson, U. Sabel, L.-G. Gustafsson, M. Sassner, and G. Destouni, "Influences of shifts in climate, landscape, and permafrost on terrestrial hydrology," Journal of Geophysical Research: Atmospheres, vol. 117, no. 5, article D05120, 2012.

[25] E. Trujillo and N. P. Molotch, "Snowpack regimes of the Western United States," Water Resources Research, vol. 50, no. 7, pp. 5611-5623, 2014.

[26] M. C. Serreze, M. P. Clark, R. L. Armstrong, D. A. McGinnis, and R. S. Pulwarty, "Characteristics of the western United States snowpack from snowpack telemetry (SNOTEL) data," Water Resources Research, vol. 35, no. 7, pp. 2145-2160, 1999.

[27] K. T. Chang and Z. Li, "Modelling snow accumulation with a geographic information system," International Journal of 
Geographical Information Science, vol. 14, no. 7, pp. 693-707, 2000.

[28] J. J. Simpson and T. J. McIntire, "A recurrent neural network classifier for improved retrievals of areal extent of snow cover," IEEE Transactions on Geoscience and Remote Sensing, vol. 39, no. 10, pp. 2135-2147, 2001.

[29] M. K. Cowles, D. L. Zimmerman, A. Christ, and D. L. McGinnis, "Combining snow water equivalent data from multiple sources to estimate spatiotemporal trends and compare measurement systems," Journal of Agricultural, Biological, and Environmental Statistics, vol. 7, no. 4, pp. 536-557, 2002.

[30] C. Powell, L. Blesius, J. Davis, and F. Schuetzenmeister, "Using MODIS snow cover and precipitation data to model water runoff for the Mokelumne River Basin in the Sierra Nevada, California (2000-2009)," Global and Planetary Change, vol. 77, no. 1-2, pp. 77-84, 2011.

[31] C. M. Welch, P. C. Stoy, F. A. Rains, A. V. Johnson, and B. L. McGlynn, "The impacts of mountain pine beetle disturbance on the energy balance of snow during the melt period," Hydrological Processes, vol. 30, no. 4, pp. 588-602, 2016.

[32] I. T. Stewart, D. R. Cayan, and M. D. Dettinger, "Changes in snowmelt runoff timing in western North America under 'a business as usual' climate change scenario," Climatic Change, vol. 62, no. 1-3, pp. 217-232, 2004.

[33] T. Barnett, J. Adam, and D. Lettenmaier, "Potential impacts of a warming climate on water availability in snow-dominated regions," Nature, vol. 438, no. 7066, pp. 303-309, 2005.

[34] B. J. Gillan, J. T. Harper, and J. N. Moore, “Timing of present and future snowmelt from high elevations in northwest Montana," Water Resources Research, vol. 46, no. 1, article W01507, 2010.

[35] H. Fritze, I. T. Stewart, and E. Pebesma, "Shifts in Western North American snowmelt runoff regimes for the recent warm decades," Journal of Hydrometeorology, vol. 12, no. 5, pp. 989-1006, 2011.

[36] K. A. Dressler, S. R. Fassnacht, and R. C. Bales, "A comparison of snow telemetry and snow course measurements in the Colorado River basin," Journal of Hydrometeorology, vol. 7, no. 4, pp. 705-712, 2006.

[37] G. E. Maurer and D. R. Bowling, "Seasonal snowpack characteristics influence soil temperature and water content at multiple scales in interior western U.S. mountain ecosystems," Water Resources Research, vol. 50, no. 6, pp. 5216-5234, 2014.

[38] H. F. Lins, USGS Hydro-Climatic Data Network 2009 (HCDN-2009), U.S. Geological Survey Fact Sheet 2012-3047, United States Geological Survey, Reston, VA, USA, 2012, http://pubs.usgs.gov/fs/2012/3047/.

[39] C. Daly, R. P. Neilson, and D. L. Phillips, "A statisticaltopographic model for mapping climatological precipitation over mountainous terrain," Journal of Applied Meteorology, vol. 33, no. 2, pp. 140-158, 1994.

[40] C. Daly, M. D. Halbleib, J. I. Smith et al., "Physiographically sensitive mapping of climatological temperature and precipitation across the conterminous United States," International Journal of Climatology, vol. 28, no. 15, pp. 2031-2064, 2008.

[41] Descriptions of PRISM Spatial Climate Datasets for the Conterminous United States, 2015.

[42] J. D. Goodridge, "A study of 1000 year storms in California," in Preprints, Predicting Heavy Rainfall Events in California: A Symposium to Share Weather Pattern Knowledge, C. Dailey, Ed., pp. 3-72, Sierra College, Rocklin, CA, USA, 1994.
[43] A. Kalra and S. Ahmad, "Evaluating changes and estimating seasonal precipitation for the Colorado River Basin using a stochastic nonparametric disaggregation technique," Water Resources Research, vol. 47, no. 5, article W05555, 2011.

[44] D. J. Seidel, Q. Fu, W. J. Randel, and T. J. Reichler, "Widening of the tropical belt in a changing climate," Nature Geoscience, vol. 1, no. 1, pp. 21-24, 2007. 

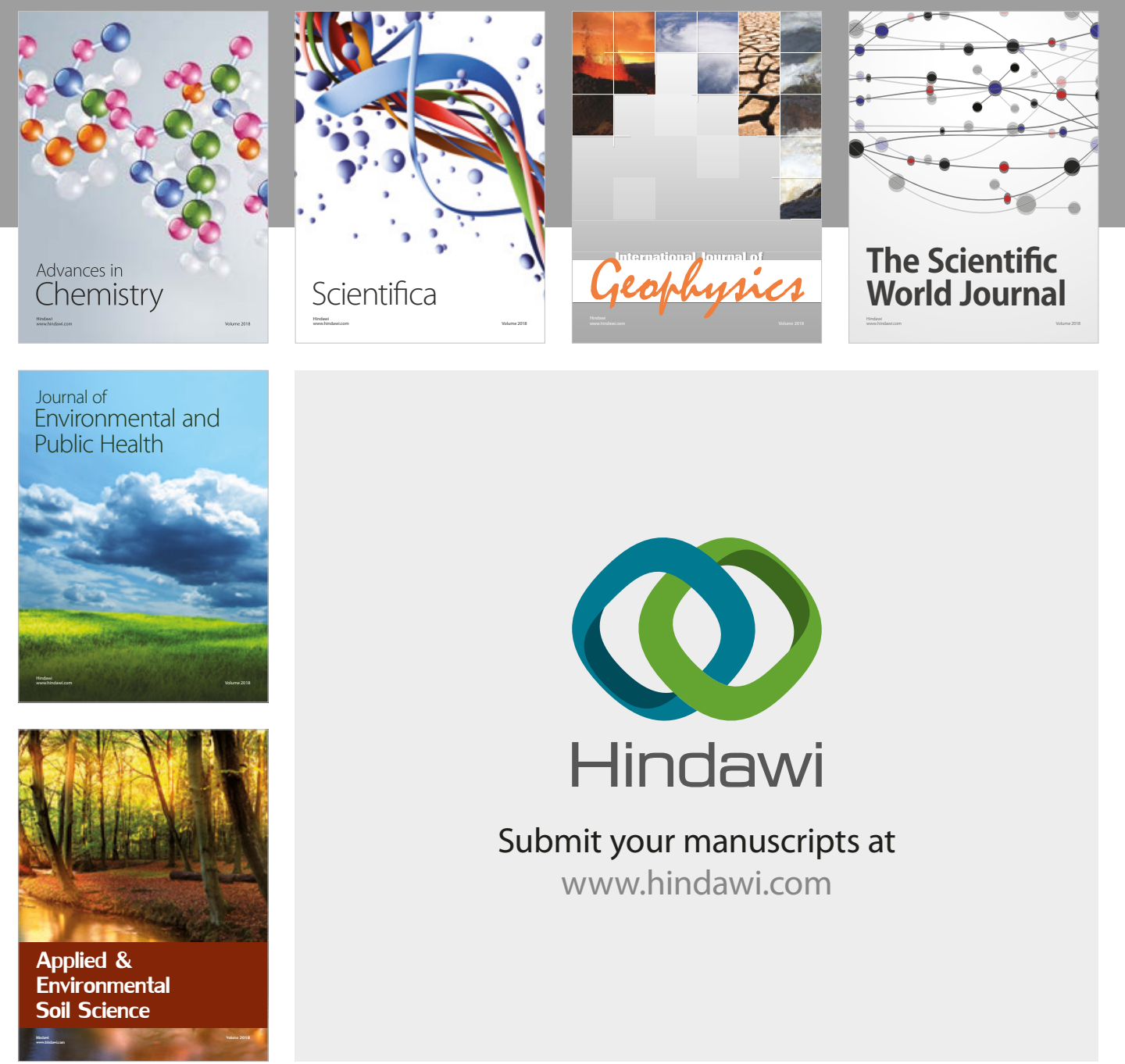

The Scientific

\section{World Journal}
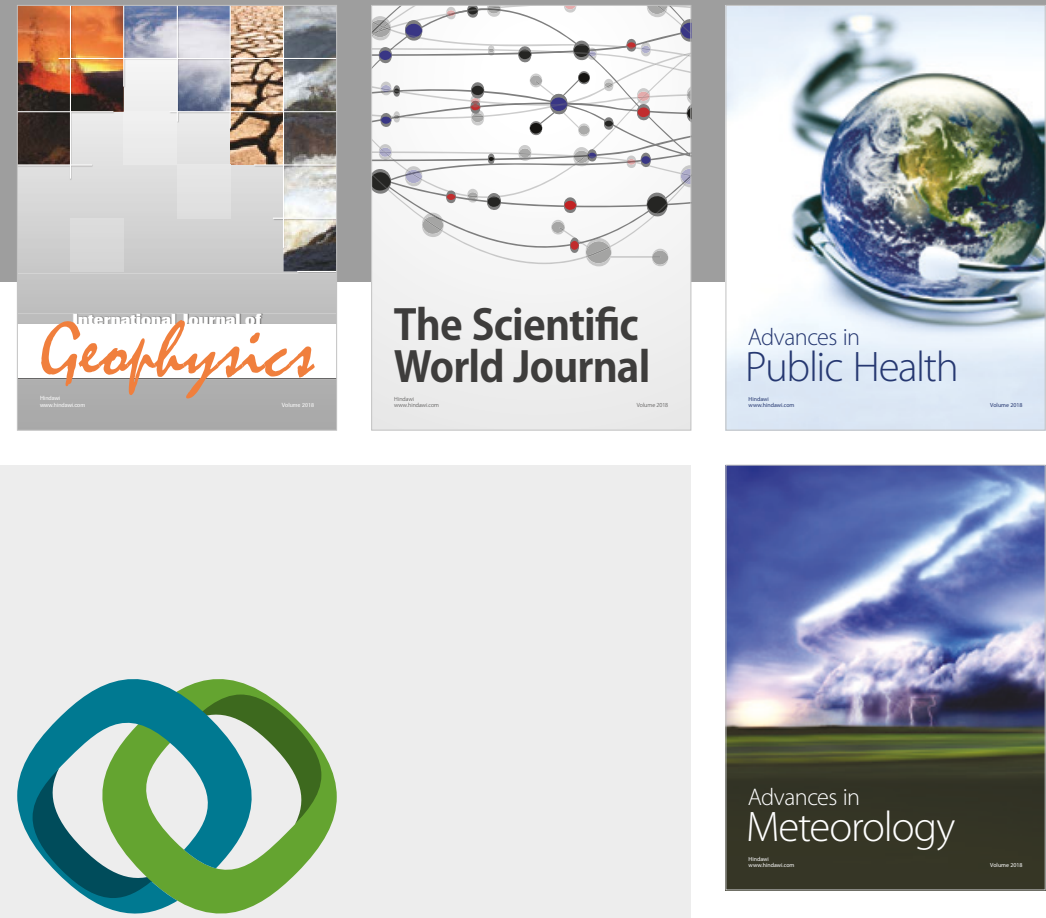

Advan

Public Health

\section{Hindawi}

Submit your manuscripts at

www.hindawi.com
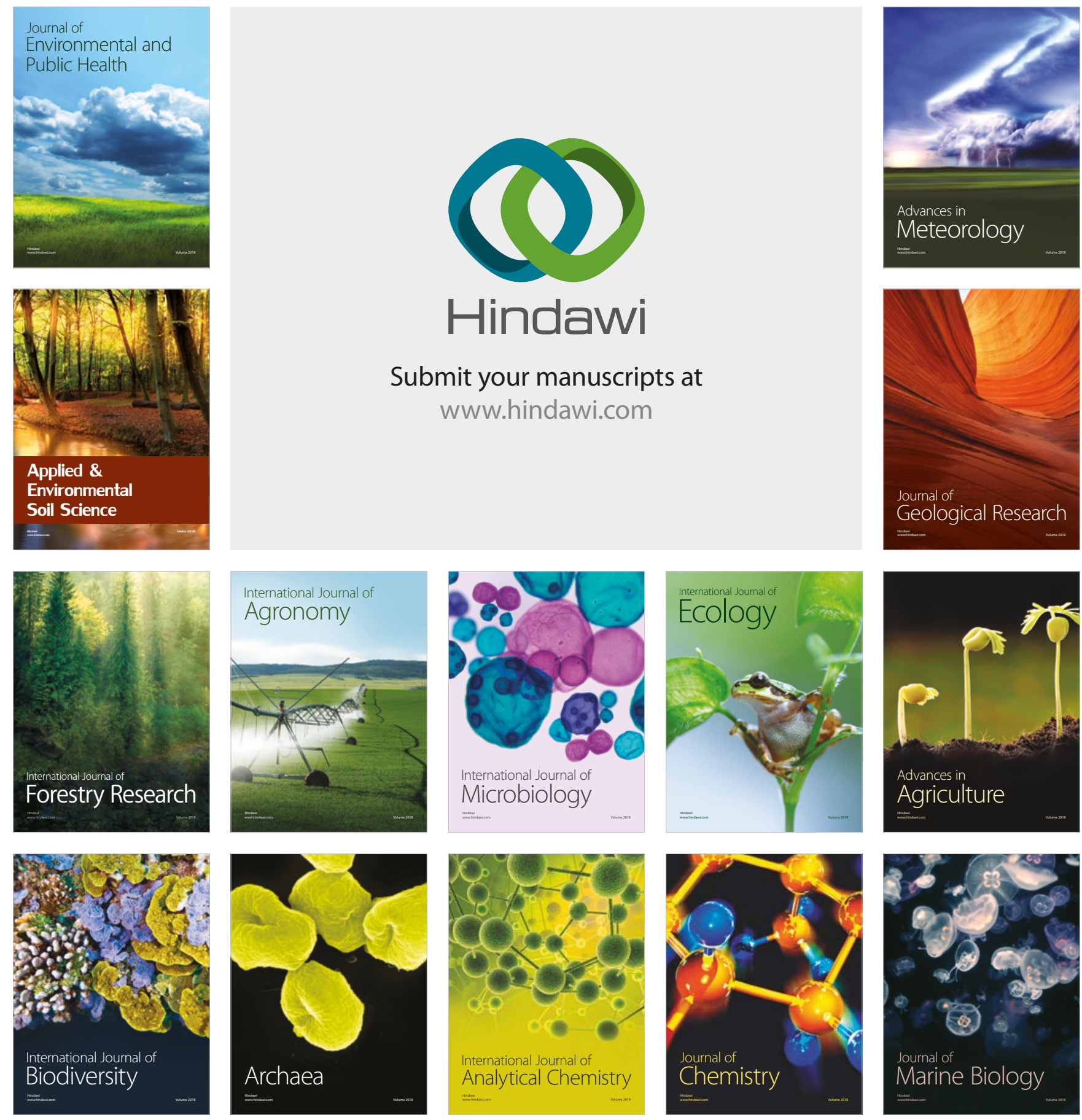